www.nature.com/pj

\title{
Polymerization of aniline under various concentrations of APS and $\mathrm{HCl}$
}

\author{
Shiow-Jing Tang ${ }^{1}$, An-Tsai Wang ${ }^{1}$, Su-Yin Lin ${ }^{2}$, Kuan-Yeh Huang ${ }^{2}$, Chun-Chuen Yang ${ }^{1}$, Jui-Ming Yeh ${ }^{2}$ \\ and Kuan-Cheng Chiu ${ }^{1}$
}

Effects from various initial molar ratios of aniline (AN), ammonium peroxydisulfate (APS) and $\mathrm{HCl}$ ([AN]:[APS]:[HCI]) on the polymerization of $A N$ were investigated. First, a scheme derived from a molecular point of view was proposed to distinguish formation mechanisms based on their initial conditions. Thereafter, by choosing a relatively low ratio of $[A P S] /[A N]=0.23$ at $[A N]=0.27 \mathrm{~m}$, three cases can be categorized according to this scheme: (A) $[\mathrm{AN}] \gg[\mathrm{HCl}]$, (B) $[\mathrm{AN}]$ slightly larger than $[\mathrm{HCl}]$ and (C) $[\mathrm{AN}]<[\mathrm{HCl}]$. For case (A), the initial solution has a richness of neutral ANs. Both the doped and the dedoped samples are confirmed to have features of phenazine-like oligomers. For case (C), neutral ANs are almost protonated to become anilinium cations. The final products possess features of polyaniline. For case (B), the samples possess both features from cases (A) and (C). Finally, the formation mechanisms for polymerization of AN were discussed.

Polymer Journal (2011) 43,667-675; doi:10.1038/pj.2011.43; published online 1 June 2011

Keywords: aniline; formation mechanism; phenazine-like oligomers; polyaniline

\section{INTRODUCTION}

Polyaniline (PANI) is one of the most important conducting and semi-conducting polymers widely used in organic optoelectronic devices and has attracted considerable attention recently because of its tunable electrical conductivity, easy preparation from common chemicals and excellent thermal and environmental stabilities. ${ }^{1,2}$ The electrical properties of PANI are sensitively dependent on its oxidation and protonation states, of which the emeraldine state (see Figure 1) with a wide range of electrical conductivity can be achieved by simple doping/dedoping chemistry based on acidic/basic reactions. ${ }^{1-3}$ The conventional chemical oxidative polymerization of aniline (AN) is carried out in a strong acidic solution and initiated by adding an oxidant (such as ammonium peroxydisulfate, APS). ${ }^{3}$ From a technical point of view, the above-mentioned preparation for PANI is a simple process, but the formation mechanism involves an intricate interplay of consecutive chemical and physical reactions. ${ }^{3-12}$

To account for the formation of PANI, the following basic mechanisms were reported. The redox reaction of neutral ANs with APS produces AN radicals. ${ }^{4}$ Under a neutral or alkaline condition, the mixed ortho-para coupling of AN radicals together with oxidative intramolecular cyclization forms AN oligomers with phenazine-like structures at the initial stage (see Figures $2 \mathrm{a}$ and $\mathrm{b}$ for phenazine and phenazine-like trimer). ${ }^{9-13}$ The oxidation of AN and AN oligomers with APS both release protons, and the $\mathrm{pH}$ of the solution falls. ${ }^{12-20}$ In a strong acidic environment, the formation of a para-coupled structure is then favored. ${ }^{4,9}$ The subsequent polymerization processes result in emeraldine salt (ES) PANI. By dedoping, emeraldine base (EB) PANI is obtained. See Figure 1 for EB PANI, and for ES PANI with separated polarons and bipolarons. ${ }^{10}$ In this model, the acidic environment has a decisive role in the formation of the obtained nanostructures. Hence, various self-assembled PANI nanostructures were reported by changing the concentration of acidic solution, the concentration ratio of AN to oxidant and reaction time during the fabrication processes. ${ }^{10-26}$

In general, there are three experimental approaches to study the effects from the acidic environment. ${ }^{5-7,10-21}$ For the first approach, using automatic titration to control a constant $\mathrm{pH}$, effects of $\mathrm{pH}$ on the morphological evolution of PANI nanostructures were discussed. ${ }^{21}$ For the second approach, by adopting $[\mathrm{APS}] /[\mathrm{AN}]=1$ or 1.25 in weak acidic or alkaline mediums (that is, starting with high $\mathrm{pH}$ ), the properties of products obtained at various moments during the strong $\mathrm{pH}$ falling were investigated..$^{5-7,10-20}$ For the third approach, by choosing $[\mathrm{APS}] /[\mathrm{AN}]=0.25-1.25$, effects of terminal $\mathrm{pH}$ on the final products were analyzed. ${ }^{20}$

Usually, polymerization of AN is carried out by choosing a fixed initial ratio of AN, oxidant and acid, and hence a detailed study of the effects from various initial conditions on the properties of the final products is also very important. In this study, at first, following the third approach as mentioned above, by adopting various values of $[\mathrm{APS}] /[\mathrm{AN}]=0.23-0.91$ in water, the profiles of $\mathrm{pH}$ falling and temperature variation were monitored. Next, by choosing a relative

${ }^{1}$ Department of Physics and Center for Nanotechnology, Chung Yuan Christian University, Chung-Li, Taiwan, ROC and ${ }^{2}$ Department of Chemistry, Chung Yuan Christian University, Chung-Li, Taiwan, ROC

Correspondence: Professor K-C Chiu, Department of Physics and Center for Nanotechnology, Chung Yuan Christian University, 200, Chung-Pei Road, Chung-Li, Taiwan 32023, ROC.

E-mail: kcchiu@cycu.edu.tw

Received 31 January 2011; revised 10 April 2011; accepted 12 April 2011; published online 1 June 2011 
<smiles>CNc1ccc(Nc2ccc(N=C3C=CC(=Nc4ccc(Br)cc4)C=C3)cc2)cc1</smiles>

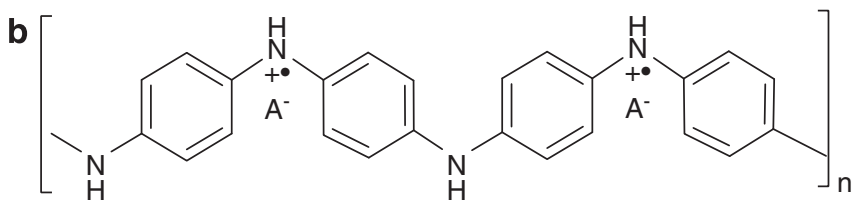<smiles>CNc1ccc(Nc2ccc(N[N+](=[Te])c3ccc(Nc4ccc(C)cc4)cc3)cc2)cc1</smiles>

$\mathrm{A}^{-}$, the counter ion, can be $\mathrm{Cl}-$ or $\mathrm{HSO}_{4}^{-}$

Figure 1 Various forms of PANI emeraldine state: (a) the emeraldine base (EB), the emeraldine salt (ES) (b) with separated polarons and (c) with bipolaron. PANI, polyaniline.

low ratio of $[\mathrm{APS}] /[\mathrm{AN}]=0.23$ for reducing the influence of $\mathrm{pH}$ falling, the effects from initial $[\mathrm{HCl}]=0-2.0 \mathrm{M}$ at $[\mathrm{AN}]=0.27 \mathrm{M}$ on the polymerization of $\mathrm{AN}$ were investigated. A scheme derived from a molecular point of view was then proposed to distinguish the formation mechanisms based on their initial conditions. Thus, three cases were categorized. Finally, the properties of the as-prepared (doped) and dedoped samples obtained from these three cases were characterized and discussed with respect to various initial conditions.

\section{EXPERIMENTAL PROCEDURE}

\section{Materials}

Aniline (98\%, Fluka, Buchs, Switzerland) was distilled under reduced pressure and stored in a refrigerator before use. APS (98\%, Fluka) was used to initiate polymerization, and $\mathrm{HCl}$ (37\%, Sigma-Aldrich, St Louis, MO, USA) was used as the doping agent.

\section{Synthesis}

Synthesis of the samples was achieved by changing [APS] $(=0.061-0.25 \mathrm{M})$, $[\mathrm{HCl}](=0-2.0 \mathrm{M})$ and $[\mathrm{AN}](=0.13$ and $0.27 \mathrm{M})$ in an aqueous solution. The typical synthesis process was as follows. At first, the proper quantities of AN and APS were dissolved in 300 and $100 \mathrm{ml}$ of $\mathrm{HCl}$ solutions (or water), respectively, with the desired concentration at $0-5^{\circ} \mathrm{C}$. After mixing the above two solutions, the reaction was proceeded for a reaction time $\tau=3.0-16 \mathrm{~h}$ in an ice bath. The precipitate was collected and dried under vacuum at $50{ }^{\circ} \mathrm{C}$ for $8.0 \mathrm{~h}$, and then the doped sample was acquired. The dedoped sample was obtained by immersing the doped sample in a $1.2 \mathrm{M} \mathrm{NH}_{4} \mathrm{OH}$ solution for at least $40 \mathrm{~h}$, and following by the similar filtering and drying processes as mentioned above.

\section{Characterization}

Fourier transform infrared (FTIR) spectrum was measured on pellets made with $\mathrm{KBr}$ at 64 scans per spectrum at $1 \mathrm{~cm}^{-1}$ resolution by using a Jasco FTIR-4200 spectrometer (Jasco, Tokyo, Japan) and corrected for the presence of carbon dioxide and water vapor in the optical path. For ultraviolet-visible (UV-Vis) spectroscopy, the samples were dissolved in NMP ( $N$-methyl pyrrolidone) and the spectrum was measured using a Shimadzu UV-2550 spectrophotometer (Shimadzu, Tokyo, Japan). As ES PANI is only slightly soluble in NMP, after an additional ultrasonic treatment for doped sample only, the solution was then taken for the measurement. The molecular weight of the dedoped sample was determined by a gel-permeation chromatography (GPC) system operating with NMP and calibrated with polystyrene standards at $35^{\circ} \mathrm{C}$. The GPC system is equipped with a<smiles></smiles>

b<smiles>N=c1ccc2nc3ccccc3n(-c3ccccc3)c-2c1</smiles>

C<smiles>Nc1ccc(N=C2C=CC(=Nc3ccc(Nc4ccccc4)cc3)C=C2)cc1</smiles>

d<smiles>Nc1ccc(Nc2ccc(N=C3C=CC(=Nc4ccc(Nc5ccc(Nc6ccc(N)cc6)cc5)cc4)C=C3)cc2)cc1</smiles><smiles>Nc1ccc(N=C2C=CC(=O)C=C2)cc1Nc1ccccc1</smiles>

Figure 2 (a) Phenazine, (b) phenazine-like aniline-trimer, (c, d) the possible phenazine-like and para-coupled structures of aniline-oligomers and (e) oxygen-containing aniline oligomers.

a Waters 1515 high-performance liquid chromatography solvent pump and a Waters 2414 refractive index detector (Waters, Milford, MA, USA). The molecular weight of the AN oligomer dissolved in methanol was performed with time-of-flight mass spectroscopy (TOF-MS) using the micrOTOF (Bruker Daltonik, Bremen, Germany). Elemental analysis of the powder sample was determined using Heraeus and Vario EL-III (Elemntar, Hanau, Germany) C, H, $\mathrm{N}$ and $\mathrm{S}$ atoms (CHNS) analyzers. The morphology of the powder sample was investigated by using Joel JSM-6335F scanning electron microscopy (SEM) (Joel, Akishima, Japan). X-ray diffraction (XRD) measurement on the powder was carried out on a Panalytical X'Pert Pro (PW 3040/60) (Panalytical, Almelo, Holland) with $\mathrm{Cu}-\mathrm{K} \alpha$ emission. For electrical characterization, the sample was pelletized using a vacuum press at 6000 psi for $5 \mathrm{~min}$, and then sandwiched by two circular Au films. The electrical conductivity of the sample $\sigma$ in vacuum at room temperature was obtained from the linear $I-V$ curve measured by using a Keithley 617 electrometer (Keithley, Solon, OH, USA) (for sample resistance $R>1 \mathrm{k} \Omega$ ) or a Keithley 2400 electrometer (for $R<1 \mathrm{k} \Omega$ with four-point method).

\section{RESULTS AND DISCUSSION}

The $\mathrm{pH}$-falling and temperature-variation profiles

To investigate the role of [APS] in the redox process, various ratios of [APS $] /[\mathrm{AN}]$ from 0.23 to 0.91 at $[\mathrm{AN}]=0.27 \mathrm{M}$ in pure water were 


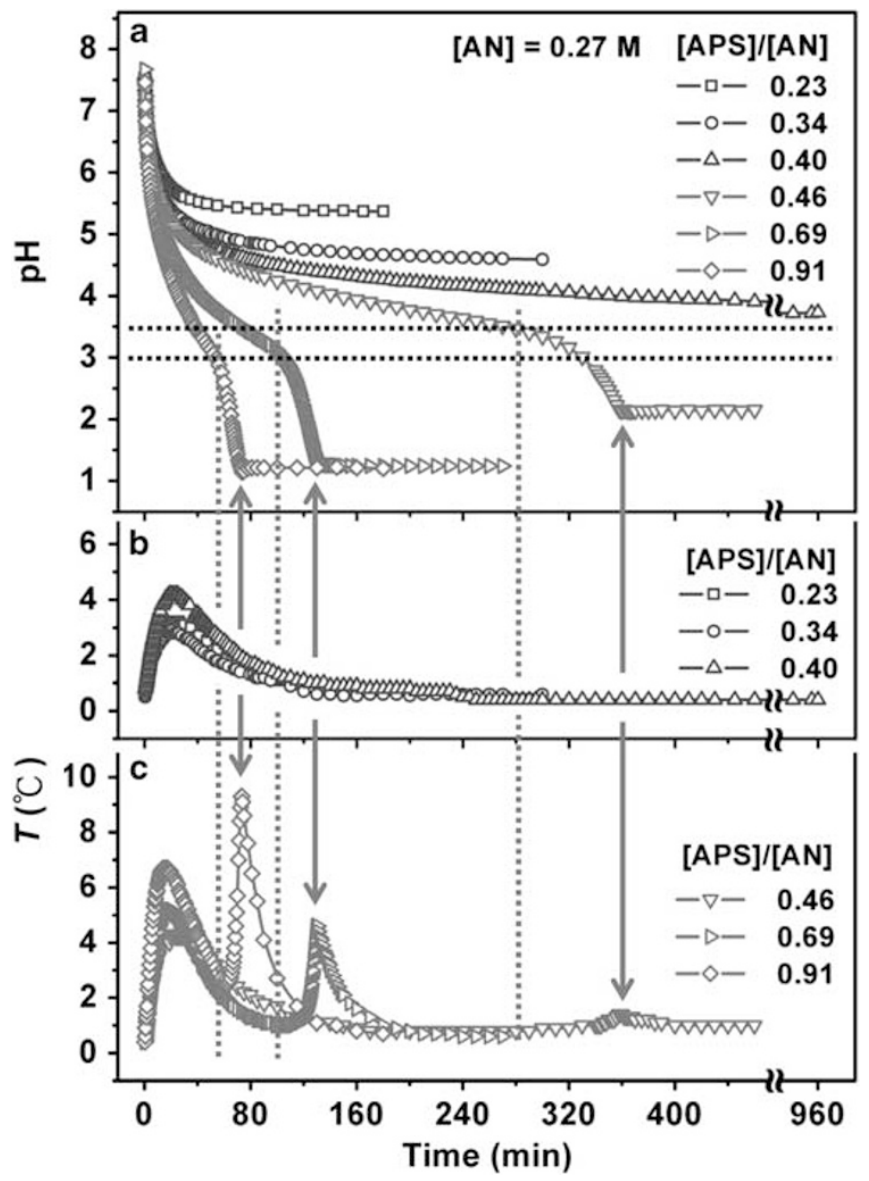

Figure 3 Variations of (a) the $\mathrm{pH}$ and $(\mathbf{b}, \mathbf{c})$ the temperature versus reaction time for various ratios of [AN]:[APS] in pure water. AN, aniline; APS, ammonium peroxydisulfate. A full color version of this figure is available at Polymer Journal online.

adopted at first. The $\mathrm{pH}$ values of the solution and the temperature at the bottom of the beaker were measured instantaneously. As shown in Figure 3, the redox reaction was started immediately as AN and APS were mixed. From the profiles of $\mathrm{pH}$ falling and temperature variation, two categories are distinguished. For $[\mathrm{APS}] /[\mathrm{AN}] \leqq 0.40$, as represented by the red brown symbols, both $\mathrm{pH}$ and temperature variations exhibit one reaction phase (because of the consumption of APS). As [APS $] /[\mathrm{AN}]=0.40$, the terminal $\mathrm{pH}$ reaches $\sim 3.7$ at $\tau=13-16 \mathrm{~h}$. For $[\mathrm{APS}] /[\mathrm{AN}] \geqq 0.46$, there are two reaction phases as represented by the green symbols. In the initial redox phase, the $\mathrm{pH}$ falls dramatically because of the strong oxidation of AN with APS (because of the richness of APS). As the $\mathrm{pH}$ reaches around 3.0-3.5, a second reaction associated with polymerization is triggered. ${ }^{11,14,18,20}$ As depicted in Figure 3, the starting and ending of polymerization are determined practically at the inflection point (as indicated by a dotted line) and at the turning point to a steady state (by a double arrow line) from each $\mathrm{pH}$ profile. Accordingly, the temperature profile increases at the start and reaches a local maximum value at the end of polymerization. Thus, for $[\mathrm{APS}] /[\mathrm{AN}] \geqq 0.46$, even for a solution with initial $\mathrm{pH} \sim 7.5$, the strong $\mathrm{pH}$ falling will effectively create high acidity to induce polymerization at the latter stage.

Therefore, by choosing a relatively low ratio of $[\mathrm{APS}] /[\mathrm{AN}]=0.23$ (instead of $[\mathrm{APS}] /[\mathrm{AN}] \geqq 1$ as conventionally adopted) at $[\mathrm{AN}]=$ $0.27 \mathrm{M}$ (to avoid the significant $\mathrm{pH}$ falling due to the richness of [APS]), effects from various [ $\mathrm{HCl}]$ on the polymerization of $\mathrm{AN}$ are shown in Figure 4. According to the profiles of $\mathrm{pH}$ falling and temperature variation, three cases can be categorized based on the initial conditions: (A) $[\mathrm{AN}] \gg[\mathrm{HCl}]$ (that is, $[\mathrm{HCl}]=0-0.10 \mathrm{M}$ as $[\mathrm{AN}]=0.27 \mathrm{M}$ ) as represented by the red brown symbols, (B) $[\mathrm{AN}]$ slightly larger than $[\mathrm{HCl}]([\mathrm{HCl}]=0.20 \mathrm{M}$ as $[\mathrm{AN}]=0.27 \mathrm{M})$ by the blue symbols and $(\mathrm{C})[\mathrm{AN}]<[\mathrm{HCl}]([\mathrm{HCl}]=0.50-2.0 \mathrm{M}$ as $[\mathrm{AN}]=0.27 \mathrm{M})$ by the green symbols. A scheme derived from a molecular point of view to distinguish these initial conditions is depicted in Figure 5. For case (A), because the protons from $\mathrm{HCl}$ are mostly used to protonate ANs, the initial $\mathrm{pH}$ of the solution is determined by the small amount of residual protons and not by the initial $[\mathrm{HCl}]$ alone. In the case of a richness of neutral ANs as shown in Figure 5, as the redox reaction of neutral ANs with APS proceeds, the $\mathrm{pH}$ falls and the temperature increases, immediately. The redox rate (as illustrated by the $\mathrm{pH}$ falling rate and the temperature increasing rate in Figures $4 \mathrm{a}$ and $\mathrm{b}$ ) decreases with increasing $[\mathrm{HCl}]$ because of the reduction of the available neutral ANs. For case (C) with a richness of protons, the initial $\mathrm{pH}$ is determined by the approximate difference of $[\mathrm{HCl}]$ and $[\mathrm{AN}]$, as indicated in Figure 4a. In such an acidic condition, the neutral ANs are almost protonated into anilinium cations, ${ }^{20}$ as also illustrated in Figure 5. Hence, the redox process of neutral ANs with APS is not triggered immediately, ${ }^{11,14,20}$ and an induction period around 4-8 min is observed before polymerization occurs (as shown in Figure 4c). For cases (A) and (C), a steady state is nearly reached for $\tau=3 \mathrm{~h}$. For case (B) with $[\mathrm{AN}]$ slightly larger than $[\mathrm{HCl}]$, as illustrated by the blue symbols in Figures $4 \mathrm{a}$ and $\mathrm{b}$, there are two reaction phases, the first one represents the redox reaction similar to that in case (A), and as the $\mathrm{pH}$ reaches $\sim 3.5$, the second one associated with polymerization is triggered.

To confirm the validity of this scheme, as shown in the inset of Figure $4 \mathrm{c}$, by fixing $[\mathrm{HCl}]=0.20 \mathrm{M}$ and $[\mathrm{APS}] /[\mathrm{AN}]=0.23$, as $[\mathrm{AN}]$ reduces from 0.27 to $0.13 \mathrm{M}$, the profile of temperature variation is transformed from case $(\mathrm{B})$ (with $[\mathrm{AN}]$ slightly larger than $[\mathrm{HCl}]$ ) to case $(\mathrm{C})$ (with $[\mathrm{AN}]<[\mathrm{HCl}]$ ).

\section{FTIR spectra}

Figure 6 depicts the characteristics of FTIR spectra for both doped and dedoped samples obtained from the initial conditions with various $[\mathrm{HCl}]$ at $[\mathrm{APS}] /[\mathrm{AN}]=0.23$ and $[\mathrm{AN}]=0.27 \mathrm{M}$. For case $(\mathrm{A})$, the main features of doped and dedoped samples are rather similar. The peak at $864 \mathrm{~cm}^{-1}$ is assigned to the 1,2,4-substituted ortho-coupled ring structures. $^{12,17,21}$ The four peaks at $1623,1445,1414$ and $1209 \mathrm{~cm}^{-1}$ are associated with ortho-coupling and branched phenazine-like structures. ${ }^{10,12,14,18,21}$ The peaks at 757, 740 and $696 \mathrm{~cm}^{-1}$ are related to the monosubstituted aromatic rings, which is associated with AN oligomers. ${ }^{12,17-19}$ As shown in Figure 6, the intensity of these eight peaks decreases slightly as $[\mathrm{HCl}]$ increases from 0 to $0.10 \mathrm{M}$. This phenomenon can be explained by the reduction in the availability of neutral ANs because of the increase of $[\mathrm{HCl}]$ and hence a decrease of the redox reaction. Thus, the signals associated with ortho-coupled phenazine-like structure and AN oligomers decrease.

For case (C), the main features of doped samples are associated with ES PANI, whereas the dedoped samples are related to EB PANI. ${ }^{27}$ The peaks at 797 and $502 \mathrm{~cm}^{-1}$ are related to the out-of-plane vibration in the 1,4-disubstituted benzene ring, that is, the para-coupling structure. ${ }^{19}$ The vibration at $797 \mathrm{~cm}^{-1}$ of ES PANI is shifted to $826 \mathrm{~cm}^{-1}$ of EB PANI. ${ }^{27}$ For doped samples, the peak at $1240 \mathrm{~cm}^{-1}$ is associated with the ' $\mathrm{C}-\mathrm{N}^{+\bullet}$ ' stretching vibration in a polaron structure, ${ }^{28}$ whereas the origins of the strong broad band around $1100-1150 \mathrm{~cm}^{-1}$ are complicated. This broad band can be decomposed into the following major peaks: the peak at $1144 \mathrm{~cm}^{-1}$ is related to the 
' $-\mathrm{NH}^{+}=$' vibration ${ }^{12,17,21,28}$ or the asymmetric stretching vibration of the sulfonate group, ${ }^{12}$ the peak at $1108 \mathrm{~cm}^{-1}$ is ascribed to the sulfateion stretching vibration ${ }^{12}$ and the peak at $1040 \mathrm{~cm}^{-1}$ is associated with $\mathrm{S}=\mathrm{O}$ vibration. ${ }^{12,14,25}$ The source of $\mathrm{S}$ atoms comes from APS adopted. After dedoping, these signals related to dopants are significantly reduced.

For samples obtained from case (B), as shown in Figure 4, because the reaction time $\tau=3 \mathrm{~h}$ has included a short period of polymerization,

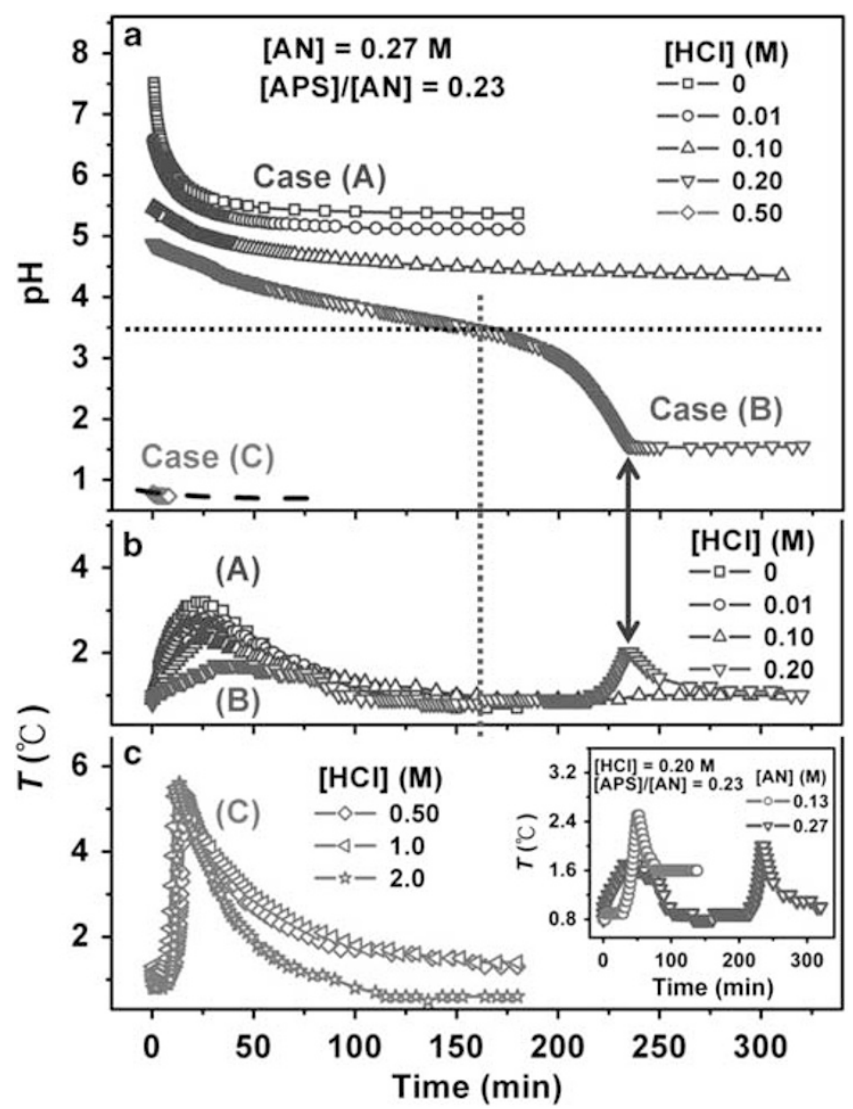

Figure 4 Variations of (a) the $\mathrm{pH}$ and $(\mathbf{b}, \mathbf{c})$ the temperature versus reaction time for various $[\mathrm{HCl}$ ( with $[\mathrm{APS}] /[\mathrm{AN}]=0.23$ at $[\mathrm{AN}]=0.27 \mathrm{~m}$ ). Case $(\mathrm{A})$ $[\mathrm{AN}] \gg[\mathrm{HCl}]$, case $(\mathrm{B})[\mathrm{AN}]>[\mathrm{HCl}]$ and case $(\mathrm{C})[\mathrm{AN}]<[\mathrm{HCl}]$. The inset in panel $\mathbf{c}$ shows the temperature variations for $[A N]=0.13$ and $0.27 \mathrm{~m}$ with $[\mathrm{HCl}]=0.20 \mathrm{M}$ and $[\mathrm{APS}] /[\mathrm{AN}]=0.23$. AN, aniline; APS, ammonium peroxydisulfate. A full color version of this figure is available at Polymer Journal online. the FTIR spectrum consists of both features from case (A) and case (C), that is, para-coupled branches growing from the phenazine-like structures. Furthermore, for cases in the inset of Figure $4 \mathrm{c}$, the corresponding FTIR spectra (although not shown here) are observed to transform from case (B) to case (C), which confirms the applicability of the scheme proposed in Figure 5.

In addition, there are two peaks at 1584 and $1511 \mathrm{~cm}^{-1}$ ascribed to the $\mathrm{C}=\mathrm{C}$ stretching vibration of quinoid and benzenoid rings, ${ }^{10,18,19,21}$ respectively, which require further discussion. For the doped samples obtained in cases (A) and (B), as $[\mathrm{HCl}]$ increases, these two peaks exhibit a slightly red shift due to the dopant effect. For case (C), these two peaks shift to 1552 and $1469 \mathrm{~cm}^{-1}$, respectively, due to the transformation from AN oligomer to ES PANI. ${ }^{18,21}$ For dedoped samples, the dopant effect is removed. Hence, the peak position at $1584 \mathrm{~cm}^{-1}$ is fixed from case (A) to case (C) because the quinoid rings are widely separated (see Figures 1 and 2), whereas its peak intensity increases from a phenazine-like structure (in which the number of quinoid rings is limited) to EB PANI. Again, the shift of peak at $1511-1494 \mathrm{~cm}^{-1}$ is due to the transformation from AN oligomer to EB PANI.

Figure 7 depicts the characteristics of FTIR spectra for doped samples obtained from initial conditions with various [APS]/[AN] at $[\mathrm{AN}]=0.27 \mathrm{M}$ in pure water, which correspond to the data in Figure 3. For $[\mathrm{APS}] /[\mathrm{AN}] \leqq 0.40$, because polymerization is not triggered, the FTIR results are similar to those obtained from case (A) in Figure 6. For $[\mathrm{APS}] /[\mathrm{AN}]=0.46$, the weak features corresponding to the para-coupling structure $\left(838\right.$ and $\left.513 \mathrm{~cm}^{-1}\right)$ and polaron structure $\left(1240 \mathrm{~cm}^{-1}\right)$ appear because of polymerization. Although for $[\mathrm{APS}] /[\mathrm{AN}]>0.46$, in a strong acidic environment induced by a fast $\mathrm{pH}$ falling, the FTIR data are close to those from case (C). However, there are two significant differences between Figures 6 and 7. First, in Figure 7, the intensities of the two peaks at 1043 and $619 \mathrm{~cm}^{-1}$, which are ascribed to $\mathrm{S}=\mathrm{O}$ and $\mathrm{S}-\mathrm{C}$ vibrations, respectively, become observable with increasing $[\mathrm{APS}]$. Second, for $[\mathrm{APS}] /[\mathrm{AN}]=0.34$ and 0.40 , a broad band with peak $\sim 1124 \mathrm{~cm}^{-1}$ appears, which represents the absorption of $\mathrm{SO}_{4}{ }^{2-}$ by the phenazine-like structure, ${ }^{29}$ and its intensity increases with increasing [APS]. The absence of this broad band in case $(\mathrm{A})$ in Figure 6 should be due to the low $[\mathrm{APS}] /[\mathrm{AN}](=0.23)$ adopted.

The above results suggest that the initial molar ratios of [AN]:[APS]:[HCl] in the solution all together have important roles in the polymerization of $\mathrm{AN}$. In the following, by fixing a low ratio of $[\mathrm{APS}] /[\mathrm{AN}]=0.23$ at $[\mathrm{AN}]=0.27 \mathrm{M}$ and with $\tau=3.0 \mathrm{~h}$, the effects from various $[\mathrm{HCl}]$ on the properties of the samples are discussed with a focus on the initial condition with a richness of either neutral ANs (for case (A)) or anilinium cations (for case (C)) as depicted in Figure 5.
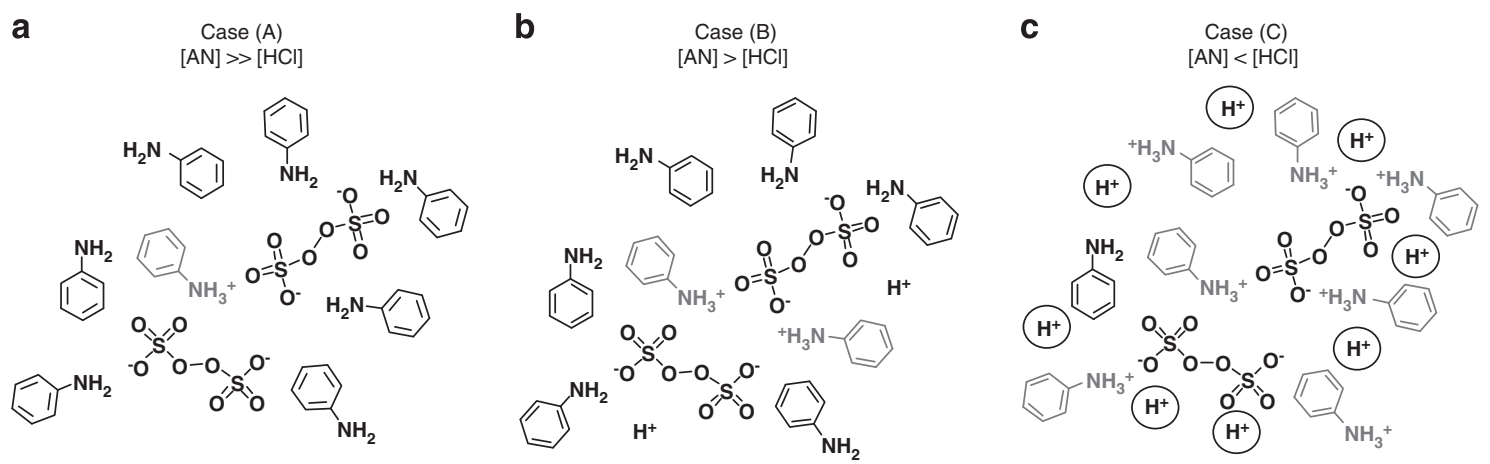

Figure 5 Schematic diagram of initial conditions for cases: (a) $[\mathrm{AN}] \gg[\mathrm{HCl}]$, (b) $[\mathrm{AN}]>[\mathrm{HCl}]$ and $(\mathbf{c})[\mathrm{AN}]<[\mathrm{HCl}]$ with $[\mathrm{APS}] /[\mathrm{AN}]=0.23$ at $[\mathrm{AN}]=0.27 \mathrm{~m}$. AN, aniline; APS, ammonium peroxydisulfate. A full color version of this figure is available at Polymer Journal online. 


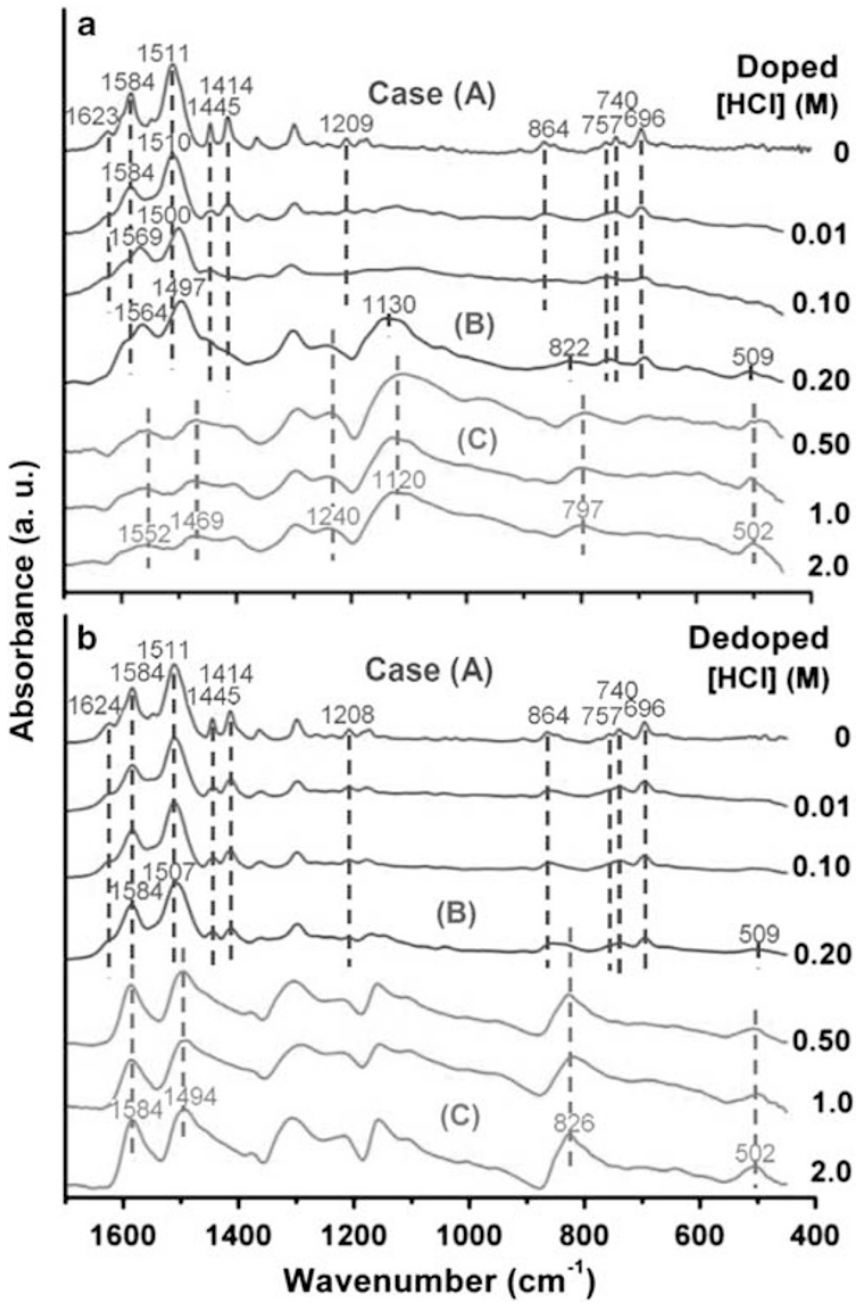

Figure 6 FTIR spectra for (a) doped and (b) dedoped samples obtained with various $[\mathrm{HCl}]$ for cases: (A) $[\mathrm{AN}] \gg[\mathrm{HCl}],(\mathrm{B})[\mathrm{AN}]>[\mathrm{HCl}]$ and $(\mathrm{C})$ $[\mathrm{AN}]<[\mathrm{HCl}]$ with $[\mathrm{APS}] /[\mathrm{AN}]=0.23$ at $[\mathrm{AN}]=0.27 \mathrm{~m}$. AN, aniline; APS, ammonium peroxydisulfate; FTIR, Fourier transform infrared. A full color version of this figure is available at Polymer Journal online.

\section{UV-Vis results}

The UV-Vis spectra of doped and dedoped samples obtained with various $[\mathrm{HCl}]$ are shown in Figure 8 . For case (A), the two strong peaks at 277 and $371 \mathrm{~nm}$ observed in both doped and dedoped samples are related to the $\pi-\pi^{*}$ transitions in substituted quinone. ${ }^{16,18,30}$ The peak at $371 \mathrm{~nm}$ may also be contributed by phenazine. ${ }^{31}$ Hence, from the UV-Vis and FTIR results, case (A) samples should be composed of the phenazine-like AN oligomers with some substituted quinones. ${ }^{14,16,18,30}$ For case (B), the shape of the spectrum is similar to that obtained from case (A), except that a shifted band at $361 \mathrm{~nm}$ (from $371 \mathrm{~nm}$ ) and a weak broad band $\sim 614 \mathrm{~nm}$ are observed, which are caused by the para-coupled branches growing from the phenazine-like structures. ${ }^{20,32}$ In addition, the color of the test solution is changed from brown for case (A) to olive for case (B). For case $(\mathrm{C})$, the main features of doped and dedoped samples are associated with ES PANI (with green color for the test solution) and EB PANI (with blue color), respectively. ${ }^{15,21-23,32-35}$ The two bands at 382 and $473 \mathrm{~nm}$ observed in the ES PANI samples are attributed to the $\pi-\pi^{*}$ transition and to the polaron- $\pi^{*}$ transition, respectively. ${ }^{15,21-23,34}$ The two bands at 325 and $631 \mathrm{~nm}$ observed in the EB PANI

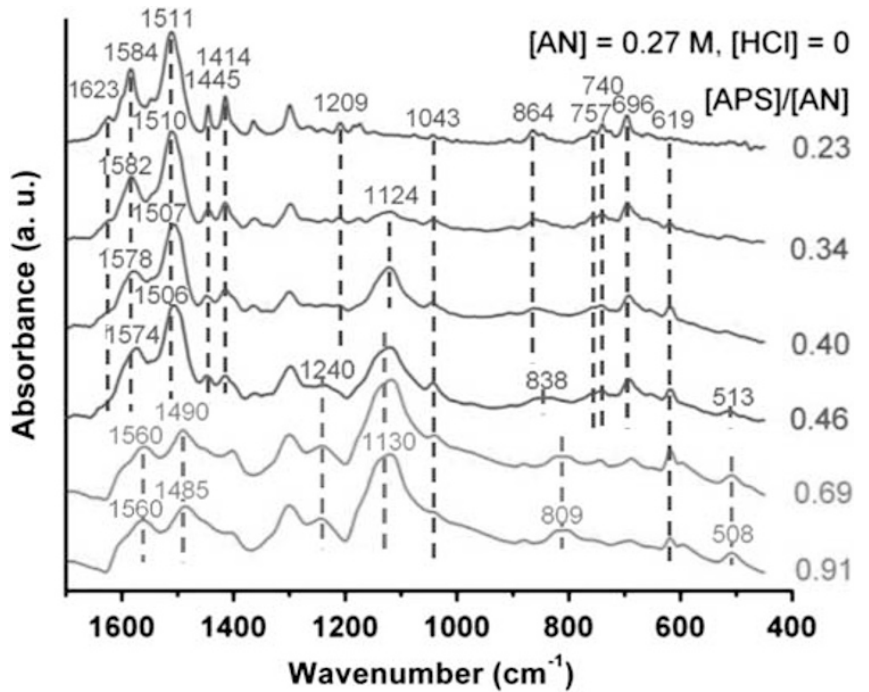

Figure $7 \mathrm{FTIR}$ spectra for doped samples obtained with various [APS]/[AN] at $[\mathrm{AN}]=0.27 \mathrm{~m}$ in pure water. AN, aniline; APS, ammonium peroxydisulfate; FTIR, Fourier transform infrared. A full color version of this figure is available at Polymer Journal online.

samples are related to the $\pi-\pi^{*}$ transition in benzenoid rings and to the charge-transfer-exciton transition formed in a benzenoid ring with its adjacent quinonoid ring, respectively. ${ }^{35}$

\section{GPC and TOF-MS results}

From our early experimental results, an existence of AN oligomers was observed to distort GPC analyses. Thus, these AN oligomers were removed by using methanol as a solvent. For case (C), the methanol solution with dissolved AN oligomers exhibits a blue color, which suggests that they are composed of short para-coupled chains. ${ }^{11,36}$ The un-dissolved PANI mass is $\sim 90 \mathrm{wt} \%$ of its original mass. For case (A), the dark brown color in the solution shows that the dissolved materials are dominant by the phenazine-like oligomers ${ }^{11,20}$ and the un-dissolved mass is $\sim 40 \mathrm{wt} \%$. This un-dissolved mass should be the aggregates of phenazine-like oligomers based on the above-mentioned FTIR and UV-Vis analyses. The molecular weights $\left(\mathrm{M}_{\mathrm{w}}\right)$ of these AN oligomers (that is, the dissolved materials) obtained from cases (A) and (B) as determined from TOF-MS are rather similar and range from 50 to 850 , as illustrated in the inset of Figure 9. The possible structures for the three peaks with $\mathrm{M}_{\mathrm{w}}$ indicated in the inset are shown in Figures 2c-e. ${ }^{10,13,14,18}$

After removing these AN oligomers, the typical GPC curve for case (C) samples exhibits two peaks. The dominant peak has a weight average $M_{w}$ related to the single chains of PANI and the other weak one has a higher $\mathrm{M}_{\mathrm{w}}$ attributed to the aggregation of EB PANI. ${ }^{37}$ As shown in Figure 9, the values of the dominant peak of $M_{w}$ for all PANI samples obtained from case (C) are ranged around 12000-22 000 with polydispersity values of around 4-6. This result is slightly smaller than that reported in previous studies $\left(M_{w}=30000-70000\right)^{12,14}$ because of the relatively low $[\mathrm{APS}] /[\mathrm{AN}]$ adopted in this study.

\section{Elemental analysis results}

From elemental analysis, the compositions of CHNS for doped and dedoped samples are listed in Table 1. The C: $\mathrm{N}$ atomic ratios derived from elemental analysis for all of the samples are very close to 6 , which are in agreement with the theoretical C:N atomic ratios for EB PANI $\left(\mathrm{C}_{24} \mathrm{H}_{18} \mathrm{~N}_{4}\right)$, ES PANI $\left(\mathrm{C}_{24} \mathrm{H}_{20} \mathrm{~N}_{4} \mathrm{Cl}_{2}\right.$ if the counter ion is $\mathrm{Cl}^{-}$, see 


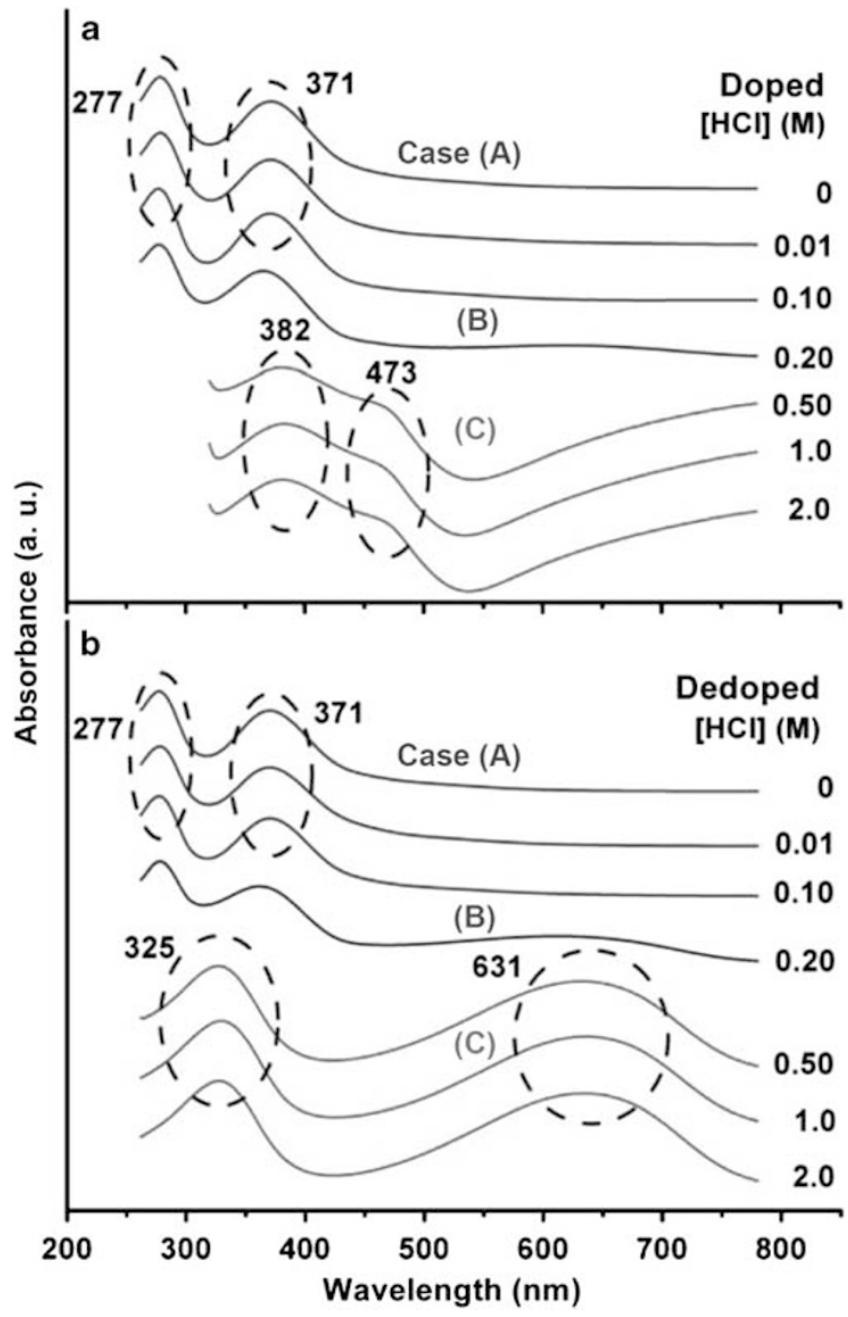

Figure 8 UV-Vis spectra for (a) doped and (b) dedoped samples obtained with various $[\mathrm{HCl}]$ for cases: (A) $[\mathrm{AN}] \gg[\mathrm{HCl}],(\mathrm{B})[\mathrm{AN}]>[\mathrm{HCl}]$ and $(\mathrm{C})$ $[\mathrm{AN}]<[\mathrm{HCl}]$ with $[\mathrm{APS}] /[\mathrm{AN}]=0.23$ at $[\mathrm{AN}]=0.27 \mathrm{~m}$. AN, aniline; APS, ammonium peroxydisulfate, UV-Vis, ultraviolet visible. A full color version of this figure is available at Polymer Journal online.

Figure 1) and phenazine molecules $\left(\mathrm{C}_{12} \mathrm{H}_{8} \mathrm{~N}_{2}\right) \cdot{ }^{3,10,38}$ On the other hand, the $\mathrm{C}: \mathrm{H}$ atomic ratios are slightly larger than the theoretical ratios. For dedoped samples, the excess $\mathrm{H}$ atoms may come from the adsorption of $\mathrm{H}_{2} \mathrm{O}$ molecules, ${ }^{39,40}$ whereas for doped samples, the source of additional $\mathrm{H}$ atoms may be due to the adsorption of $\mathrm{HCl}$ or $\mathrm{H}_{2} \mathrm{SO}_{4}$ molecules (see Figure 1). It must be noted that $\mathrm{H}_{2} \mathrm{SO}_{4}$ is a byproduct of the redox reaction of AN with APS. ${ }^{10,12,14}$ In addition, the small amount of $\mathrm{S}$ observed in the doped samples is significantly reduced after dedoping. This fact suggests that these easily removed $\mathrm{S}$ atoms originate from the adsorbed $\mathrm{H}_{2} \mathrm{SO}_{4}$ molecules. However, in dedoped samples produced from case (A), a trace of $\mathrm{S}$ is still detected. These residual $\mathrm{S}$ atoms come from a covalent bond formed during the reaction. ${ }^{12}$

From the subtotal weight percentage of CHNS as listed in Table 1, the origins from two other $\mathrm{Cl}$ and $\mathrm{O}$ atoms are discussed as follows. For all dedoped samples, the values of the subtotal weight percentage of CHNS are nearly independent of $[\mathrm{HCl}]$ with an approximate average of $93 \pm 2 \%$. The source of this deviation from unity is assumed to be from the $\mathrm{O}$ atoms, which can be from adsorbed $\mathrm{H}_{2} \mathrm{O}$ molecules $^{3,39,40}$ or oxygen-containing oligomers ${ }^{3,10,13,41}$ (see Figure 2e).

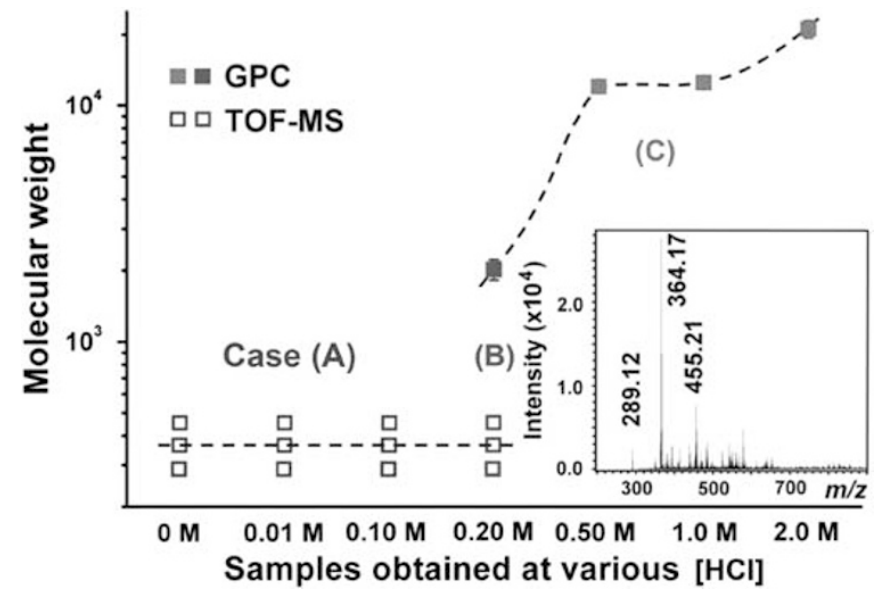

Figure $9 \mathrm{GPC}$ and TOF-MS results of dedoped samples obtained with various $[\mathrm{HCl}]$ for cases: (A) $[\mathrm{AN}] \gg[\mathrm{HCl}], \quad(B)[\mathrm{AN}]>[\mathrm{HCl}]$ and $(\mathrm{C})$ $[\mathrm{AN}]<[\mathrm{HCl}]$ with $[\mathrm{APS}] /[\mathrm{AN}]=0.23$ at $[\mathrm{AN}]=0.27 \mathrm{~m}$. The inset shows a typical mass spectroscopy for case (A). AN, aniline; APS, ammonium peroxydisulfate; GPC, gel-permeation chromatography; TOF-MS, time-offlight mass spectroscopy. A full color version of this figure is available at Polymer Journal online.

If the $\mathrm{O}$ atoms are mainly from the adsorbed $\mathrm{H}_{2} \mathrm{O}$ molecules, by subtracting twice the atomic ratios of the $\mathrm{O}$ atom from the atomic ratios of the $\mathrm{H}$ atom as listed in Table 1, then, the corrected atomic ratios of the $\mathrm{H}$ atom in these dedoped samples are close to those expected.

For doped samples in case (A), the values of the subtotal weight percentage of CHNS are slightly smaller than those in dedoped samples, correspondingly. This phenomenon indicates a weak dopant effect. Furthermore, this subtotal changes significantly from $88 \%$ at $[\mathrm{HCl}]=0.10 \mathrm{M}$ (case $(\mathrm{A}))$ to $75 \%$ at $[\mathrm{HCl}]=0.20 \mathrm{M}$ (case (B)), and approaches $71 \%$ in case $(\mathrm{C})$. For samples in case (B), because polymerization is triggered, the para-coupled PANI chains with dopants are grown from phenazine-like structures (as confirmed by the FTIR signals). ${ }^{13,14}$ Thus, for cases (B) and (C) with PANI chains, these low subtotals indicate a strong adsorption of $\mathrm{HCl}$ or $\mathrm{H}_{2} \mathrm{SO}_{4}$. As no information is available about the relative ratio of $\mathrm{Cl}: \mathrm{O}$, the atomic ratios of $\mathrm{Cl}$ and $\mathrm{O}$ cannot be estimated.

\section{SEM results}

Figure 10 shows the SEM images of doped samples obtained from various cases. For case (A), a petal-like structure intersected by many nanosheets of thickness $\sim 30 \mathrm{~nm}$ is formed by the stacking of planar phenazine-like oligomers. ${ }^{10,18}$ For case (C), the whole surface is composed of many tiny coral reefs closely covered with nanogranules, and in between these coral reefs some nanofibers of diameter $<10 \mathrm{~nm}$ can be distinguished (see the inset in Figure 10). These nanogranules/ nanofiber are formed by the self-assembled PANI. ${ }^{18,21}$ For case (B) with a mixture of phenazine-like oligomers and PANI, a composite feature is observed. The morphologies of the dedoped samples are similar to those of the doped samples and are not shown here. This similarity may be due to the fact that the doped samples obtained here were under vacuum drying at $50^{\circ} \mathrm{C}$ for $8 \mathrm{~h}$, and thus, a relatively rigid stacking frame was formed.

\section{XRD results}

Figure 11 shows the XRD patterns of samples obtained from various cases. From the data of the $\alpha$-phenazine structure (monoclinic, 
Table 1 Elemental analysis results of doped and dedoped samples obtained with various $[\mathrm{HCl}]$ with $[$ APS $] /[$ AN $]=0.23$ at $[$ AN $]=0.27 \mathrm{~m}$

\begin{tabular}{|c|c|c|c|c|c|c|c|}
\hline \multirow[b]{2}{*}{ Case } & \multirow{2}{*}{$\begin{array}{l}{[\mathrm{HCl}]} \\
(\mathrm{M})\end{array}$} & \multicolumn{4}{|c|}{ Atomic ratio } & \multirow{2}{*}{$\begin{array}{l}\text { Subtotal } \\
\text { (wt\%) }\end{array}$} & \multirow{2}{*}{$\begin{array}{l}\text { By difference (atomic ratio) } \\
\qquad \mathrm{Cl}+\mathrm{O}\end{array}$} \\
\hline & & c & $H$ & $N$ & $S$ & & \\
\hline \multirow[t]{3}{*}{ (A) } & 0 & $6.00 \pm 0.05$ & $5.08 \pm 0.60$ & $0.99 \pm 0.02$ & $0.06 \pm 0.03$ & $91.5 \pm 2.2$ & - \\
\hline & 0.01 & $6.00 \pm 0.03$ & $6.30 \pm 0.23$ & $1.03 \pm 0.02$ & $0.12 \pm 0.01$ & $87.8 \pm 0.9$ & - \\
\hline & 0.10 & $6.00 \pm 0.05$ & $6.32 \pm 0.42$ & $1.09 \pm 0.02$ & $0.15 \pm 0.01$ & $87.7 \pm 1.4$ & - \\
\hline \multirow{3}{*}{ (C) } & 1.0 & $6.00 \pm 0.04$ & $7.89 \pm 0.32$ & $1.01 \pm 0.02$ & $0.04 \pm 0.01$ & $71.9 \pm 1.2$ & - \\
\hline & 2.0 & $6.00 \pm 0.04$ & $8.76 \pm 0.52$ & $1.07 \pm 0.03$ & $0.14 \pm 0.03$ & $70.7 \pm 1.5$ & - \\
\hline & & & & & & & 0 \\
\hline \multicolumn{8}{|c|}{ Dedoped } \\
\hline \multirow[t]{3}{*}{ (C) } & 0.50 & $6.00 \pm 0.03$ & $5.36 \pm 0.28$ & $0.99 \pm 0.02$ & $0.00 \pm 0.01$ & $95.2 \pm 1.1$ & $0.30 \pm 0.07$ \\
\hline & 1.0 & $6.00 \pm 0.05$ & $5.46 \pm 0.44$ & $1.00 \pm 0.02$ & $0.00 \pm 0.01$ & $93.6 \pm 1.5$ & $0.40 \pm 0.10$ \\
\hline & 2.0 & $6.00 \pm 0.03$ & $5.68 \pm 0.37$ & $0.98 \pm 0.02$ & $0.00 \pm 0.01$ & $90.9 \pm 1.2$ & $0.57 \pm 0.08$ \\
\hline
\end{tabular}

Abbreviations: AN, aniline; APS, ammonium peroxydisulfate.

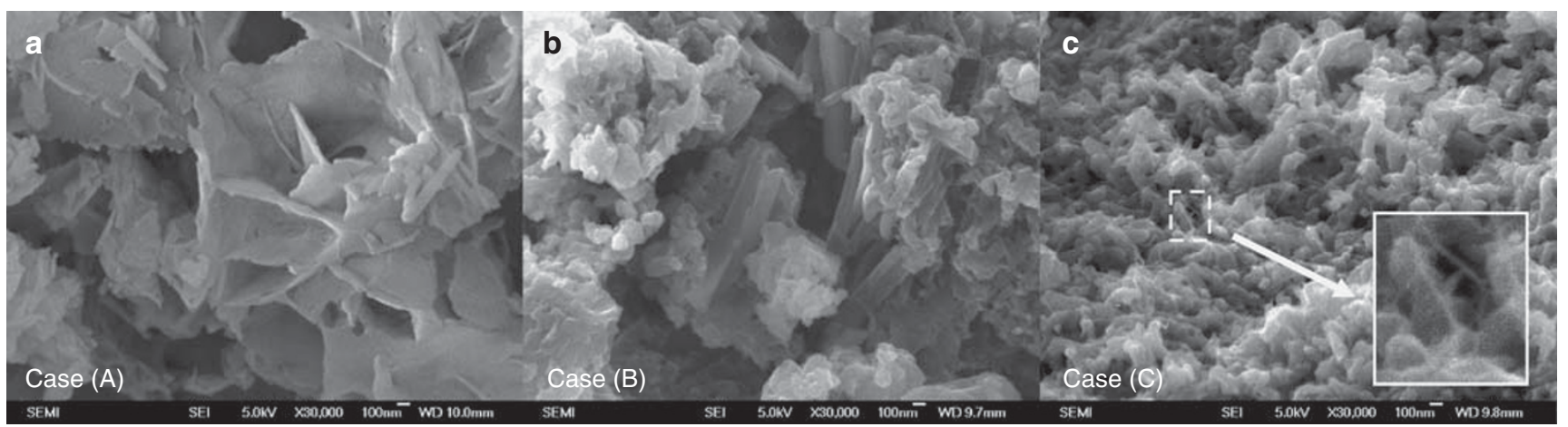

Figure 10 SEM images of doped samples obtained for cases: (a) $[\mathrm{AN}] \gg[\mathrm{HCl}]$, (b) $[\mathrm{AN}]>[\mathrm{HCl}]$ and (c) $[\mathrm{AN}]<[\mathrm{HCl}]$ with $[\mathrm{APS}] /[\mathrm{AN}]=0.23$ at $[\mathrm{AN}]=0.27 \mathrm{M}$. AN, aniline; APS, ammonium peroxydisulfate; SEM, scanning electron microscopy.

$\left.a=7.1 \AA, b=5.1 \AA, c=12.8 \AA, \beta=102.3^{\circ}\right),{ }^{38}$ we calculated and assigned the distinguishable peaks to their corresponding planes as indicated in Figure 11a. Thus, samples obtained from case (A) are confirmed to be composed of phenazine segments with order stacking. After dedoping, some facets of the $\alpha$-phenazine structure with high surface energy may disappear and only a few facets persistently remain as depicted in Figure 11b.

As shown in Figure 11a, for case (C), the ES PANI samples have weak crystallinity with a pseudo-orthorhombic structure $(a=4.3 \AA$, $b=5.9 \AA, c=9.6 \AA)$, and the corresponding peaks are assigned. ${ }^{42}$ This crystallinity is caused by the counter-ions $\left(\mathrm{Cl}^{-}\right.$or $\left.\mathrm{HSO}_{4}^{-}\right)$ accompanying the protons near the $\mathrm{N}$ atoms (see Figure 1 for PANI with polarons and bipolarons), which provide the necessary electrostatic forces for inducing a higher degree of chain ordering. ${ }^{42,43}$ After the dedoping process to remove these absorbed dopants, the ordering between these chains is reduced and thus the EB PANI samples become amorphous as shown in Figure 11b.

For case (B), especially for the dedoped one, although the sample retains the composite feature of cases (A) and (C), the XRD result is close to that from case (A) because of the amorphous character of case (C) samples.

Formation mechanism-revised and electrical characterization As shown in Figure 5, three cases based on their initial conditions can be categorized according to this proposed scheme, which is derived from a molecular point of view. For case $(\mathrm{A})$ with $[\mathrm{AN}] \gg[\mathrm{HCl}]$, the immediate redox reaction of neutral ANs with APS produces AN radicals. Under a neutral or weak acidic environment, the mixed ortho-para coupling of these AN radicals together with the oxidative intramolecular cyclization forms phenazine-like nucleus (see Figure $2 \mathrm{~b}),{ }^{13}$ and finally phenazine-like oligomers are obtained, as confirmed by FTIR, UV-Vis and TOF-MS data. In case (A), because of the consumption of APS, the reaction ceases with a terminal $\mathrm{pH}>4.3$. Through $\pi-\pi$ stacking between these planar phenazine-like structures, ${ }^{14}$ a surface morphology with nanosheets observed by SEM together with its crystallinity identified by XRD are then obtained. Owing to the lack of long conjugated length in these phenazine-like oligomers and the relatively high energy gap of the $\pi-\pi^{\star}$ transition 


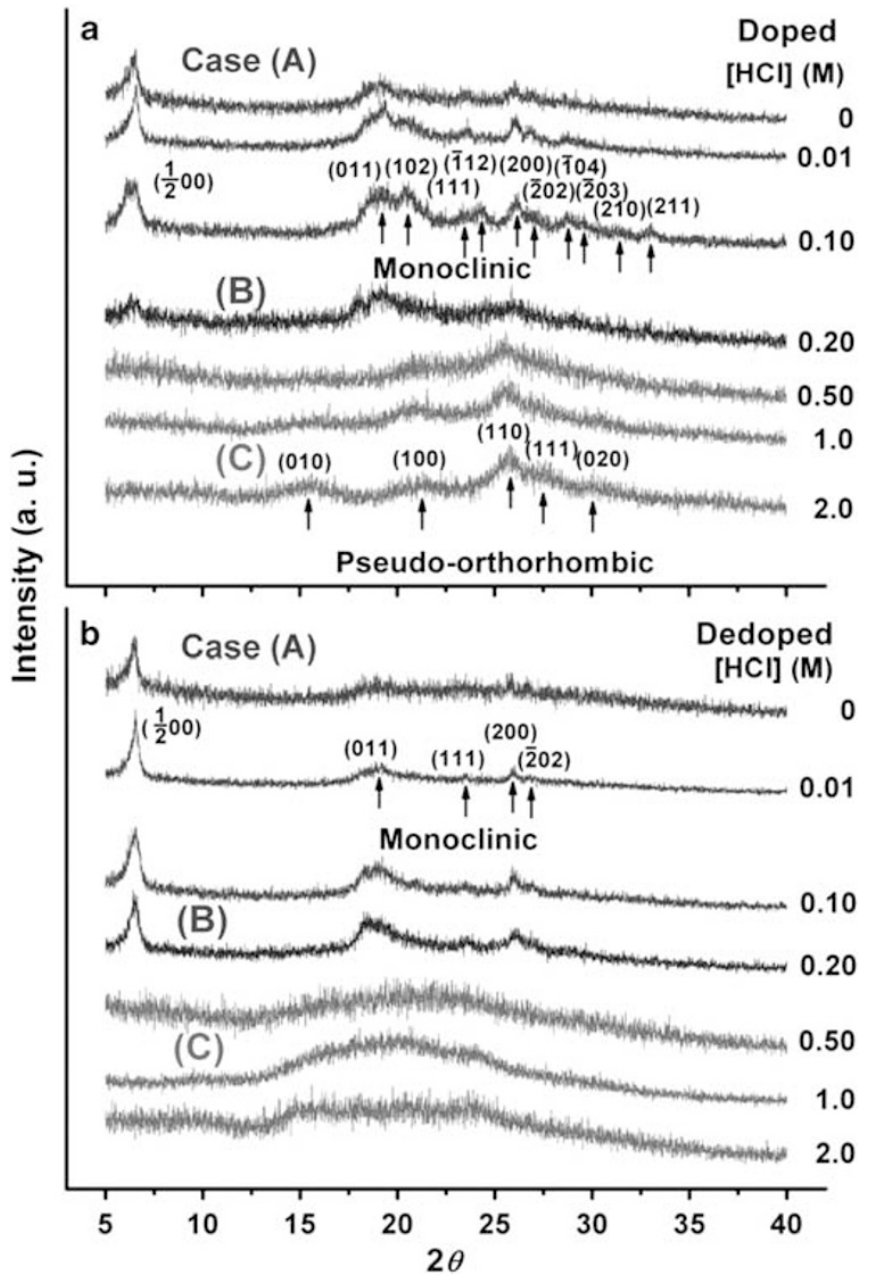

Figure 11 XRD spectra for (a) doped and (b) dedoped samples obtained for cases: (A) $[\mathrm{AN}] \gg[\mathrm{HCl}],(\mathrm{B})[\mathrm{AN}]>[\mathrm{HCl}]$ and $(\mathrm{C})[\mathrm{AN}]<[\mathrm{HCl}]$ with $[\mathrm{APS}] /$ $[A N]=0.23$ at $[A N]=0.27 \mathrm{~m}$. AN, aniline; APS, ammonium peroxydisulfate; XRD, X-ray diffraction. A full color version of this figure is available at Polymer Journal online.

(371 nm as shown in Figure 8), both doped and dedoped samples obtained at $[\mathrm{HCl}]=0.10 \mathrm{M}$ possess a rather low $\sigma$ of $(2 \pm 1) \times$ $10^{-13} \mathrm{~S} \mathrm{~cm}^{-1}$.

For case $(\mathrm{C})$ with $[\mathrm{AN}]<[\mathrm{HCl}]$, the neutral ANs are almost protonated into anilinium cations at the beginning. ${ }^{20}$ These anilinium cations are difficult to be oxidized directly because the electron pair on nitrogen is localized, ${ }^{14}$ and hence an induction period is observed. Once these anilinium cations are deprotonated, the redox reaction of neutral AN with APS produces AN radicals. ${ }^{44}$ Meanwhile, in a strong acidic environment, these AN radicals are favored to form a para-coupled oligomer. ${ }^{4,9,11}$ As the configuration of this oligomer reaches its maximum conjugation and charge delocalization, a rapid polymerization is stimulated by addition of protonated anilinium cations. ${ }^{13,14}$ Thus, longer PANI chains are obtained and confirmed by FTIR, UV-Vis and GPC data. Through various interchain/intrachain interactions (such as H-bonding, $\pi-\pi$ interaction, van der Waals bonding and entanglement), the PANI chains can then aggregate to form nanofibers and/or nanogranules as shown in SEM pictures. ${ }^{13,16,21,26,28,45}$ Owing to the long conjugated length and the polaron band induced by dopants, ${ }^{15,21-23,34}$ the ES PANI samples obtained at $[\mathrm{HCl}]=1.0 \mathrm{M}$ possess a high $\sigma$ of $(4 \pm 2) \times 10^{-2} \mathrm{~S} \mathrm{~cm}^{-1}$; after dedoping, $\sigma$ of the EB PANI samples is dramatically reduced to $(7 \pm 1) \times 10^{-11} \mathrm{~S} \mathrm{~cm}^{-1}$. The crystallinity caused by the dopants for ES PANI, in contrast to the amorphous character of EB PANI, is identified by XRD.

For case (B) with $[\mathrm{AN}]$ slightly larger than $[\mathrm{HCl}]$, the concentration of neutral AN is smaller than that of anilinium cation at the beginning. ${ }^{20}$ The oxidation of this small amount of neutral AN by APS and the formation into phenazine-like oligomers are carried out immediately, which is similar to case (A). As the neutral AN is consumed, some APS and anilinium cations are still left in this case. An additional induction period is required for further reactions of these residual APS and anilinium cations, which is similar to case (C). As the conjugated length is long enough, polymerization is triggered. ${ }^{13,14}$ Thus, both features of phenazine-like oligomers and PANI are presented and confirmed by FTIR, UV-Vis, TOF-MS and GPC data. For the doped sample in case (B), although containing some non-conducting phenazine-like oligomers, a high $\sigma$ of $(3 \pm 1) \times$ $10^{-2} \mathrm{~S} \mathrm{~cm}^{-1}$ (slightly smaller than the one obtained at $[\mathrm{HCl}]=1 \mathrm{M}$ ) indicates that the charge transport through the conducting ES PANI chains is above the percolation threshold. ${ }^{46,47}$ Again, by dedoping, a low $\sigma$ of $(6 \pm 3) \times 10^{-11} \mathrm{~S} \mathrm{~cm}^{-1}$ is obtained.

\section{ACKNOWLEDGEMENTS}

This study was supported by the National Science Council of the Republic of China. We thank Professor W L Abels and Mrs C H Abels for their editorial assistance.

1 Moliton, A. \& Hiorns, R. C. Review of electronic and optical properties of semiconducting $\pi$-conjugated polymers: applications in optoelectronics. Polym. Int. 53, 1397-1412 (2004).

2 Heeger, A. J. Semiconducting and metallic polymers: the fourth generation of polymeric materials. Synth. Met. 125, 23-42 (2002).

3 Chiang, J. C. \& MacDiarmid, A. G. 'Polyaniline': protonic acid doping of the emeraldine form to the metallic regime. Synth. Met. 13, 193-205 (1986).

4 Stejskal, J., Kratochvil, P. \& Jenkins, A. D. The formation of polyaniline and the nature of its structures. Polymer 37, 367-369 (1996).

5 Gospodinova, N., Terlemezyan, L., Mokreva, P. \& Kossev, K. On the mechanism of oxidative polymerization of aniline. Polymer 34, 2434-2437 (1993).

6 Gospodinova, N., Mokreva, P. \& Terlemezyan, L. Chemical oxidative polymerization of aniline in aqueous medium without added acids. Polymer 34, 2438-2439 (1993).

7 Gospodinova, N. \& Terlemezyan, L. Conducting polymers prepared by oxidative polymerization: polyaniline. Prog. Polym. Sci. 23, 1443-1484 (1998).

8 Tzou, K. \& Gregory, R. V. Kinetic study of the chemical polymerization of aniline in aqueous solutions. Synth. Met. 47, 267-277 (1992).

9 Ciric-Marjanovic, G., Trchova, M. \& Stejskal, J. Theoretical study of the oxidative polymerization of aniline with peroxydisulfate: tetramer formation. Int. J. Quantum. Chem. 108, 318-333 (2008).

10 Zujovic, Z. D., Zhang, L., Bowmaker, G. A., Kilmartin, P. A. \& Travas-Sejdic, J. Self-assembled, nanostructured aniline oxidation products: a structural investigation. Macromolecules 41, 3125-3135 (2008).

11 Stejskal, J., Sapurina, I. \& Trchova, M. Polyaniline nanostructures and the role of aniline oligomers in their formation. Prog. Polym. Sci. 35, 1410-1481 (2010).

12 Trchova, M., Sedenkova, I., Konyushenko, E. N., Stejskal, J., Holler, P. \& CiricMarjanovic, G. Evolution of polyaniline nanotubes: the oxidation of aniline in water. J. Phys. Chem. B 110, 9461-9468 (2006).

13 Sapurina, I. \& Stejskal, J. The mechanism of the oxidative polymerization of aniline and the formation of supramolecular polyaniline structures. Polym. Int. 57, 1295-1325 (2008).

14 Stejskal, J., Sapurina, I., Trchova, M. \& Konyushenko, E. N. Oxidation of aniline: polyaniline granules, nanotubes, and oligoaniline microspheres. Macromolecules 41, 3530-3536 (2008).

15 Huang, Y. F. \& Lin, C. W. Introduction of methanol in the formation of polyaniline nanotubes in an acid-free aqueous solution through a self-curling process. Polymer 50 , 775-782 (2009).

16 Venancio, E. C., Wang, P. C. \& MacDiarmid, A. G. The azanes: a class of material incorporating nano/micro self-assembled hollow spheres obtained by aqueous oxidative polymerization of aniline. Synth. Met. 156, 357-369 (2006).

17 Zhang, L., Zujovic, Z. D., Peng, H., Bowmaker, G. A., Kilmartin, P. A. \& Travas-Sejdic, J. Structural characteristics of polyaniline nanotubes synthesized from different buffer solutions. Macromolecules 41, 8877-8884 (2008). 
18 Zujovic, Z. D., Laslau, C., Bowmaker, G. A., Kilmartin, P. A., Webber, A. L., Brown, S. P. \& Travas-Sejdic, J. Role of aniline oligomeric nanosheets in the formation of polyaniline nanotubes. Macromolecules 43, 662-670 (2010).

19 Ding, H., Shen, J., Wan, M. \& Chen, Z. Formation mechanism of polyaniline nanotubes by a simplified template-free method. Macromol. Chem. Phys. 209, 864-871 (2008).

20 Konyushenko, E. N., Trchova, M., Stejskal, J. \& Sapurina, I. The role of acidity profile in the nanotunular growth of polyaniline. Chem. Pap. 64, 56-64 (2010).

21 Laslau, C., Zujovic, Z. D., Zhang, L., Bowmaker, G. A. \& Travas-Sejdic, J. Morphological evolution of self-assembled polyaniline nanostuctures obtained by $\mathrm{pH}$-stat chemical oxidation. Chem. Mater. 21, 954-962 (2009).

22 Li, G., Pang, S., Xie, G., Wang, Z., Peng, H. \& Zhang, Z. Synthesis of radially aligned polyaniline dendrites. Polymer 47, 1456-1549 (2006).

23 Li, G., Zhang, C., Li, Y., Peng, H. \& Chen, K. Rapid polymerization initiated by redox initiator for the synthesis of polyaniline nanofibers. Polymer 51, 1934-1939 (2010).

24 Ding, Z., Currier, R. P., Zhao, Y. \& Yang, D. Self-assembled polyaniline nanotubes with rectangular cross-sections. Macromol. Chem. Phys. 210, 1600-1606 (2009).

25 Wang, J., Wang, J., Yang, Z., Wang, Z., Zhang, F. \& Wang, S. A novel strategy for the synthesis of polyaniline nanostructures with controlled morphology. React. Funct. Polym. 68, 1435-1440 (2008)

26 Pan, L., Pu, L., Shi, Y., Sun, T., Zhang, R. \& Zheng, Y. Hydrothermal synthesis of polyaniline mesostructures. Adv. Funct. Mater. 16, 1279-1288 (2006).

27 Ohira, M., Sakai, T., Takeuchi, M., Kobayashi, Y. \& Tsuji, M. Raman and infrared spectra of polyaniline. Synth. Met. 18, 347-352 (1987).

28 Shao, L., Qiu, J. H., Feng, H. X., Liu, M. Z., Zhang, G. H., An, J. B., Gao, C. M. \& Liu, H. L. Structural investigation of lignosulfonate doped polyaniline. Synth. Met. 159, 1761-1766 (2009).

29 Komura, T., Ishihara, M., Yamaguchi, T. \& Takahashi, K. Charge-transporting properties of electropolymerized phenosafranin in aqueous media. J. Electroanal. Chem. 493, 84-92 (2000).

30 Surwade, S. P., Dua, V., Manohar, N., Manohar, S. K., Beck, E. \& Ferraris, J. P. Oligoaniline intermediates in the aniline-peroxydisulfate system. Synth. Met. 159, 445-455 (2009).

31 Bailey, G. W. \& Karickhoff, S. W. An ultraviolet spectroscopic method for monitoring surface acidity of clay minerals under varying water content. Clays Clay Miner. 21, 471-477 (1973).

32 Zhang, W. J., Feng, J., MacDiarmid, A. G. \& Epstein, A. J. Synthesis of oligomeric anilines. Synth. Met. 84, 119-120 (1997).

33 Hung, J., Virji, S., Weiller, B. H. \& Kaner, R. B. Polyaniline nanofibers: facile synthesis and chemical sensors. J. Am. Chem. Soc. 125, 314-315 (2003).
34 Xia, Y., Wiesinger, J. M., MacDiarmid, A. G. \& Epstein, A. J. Camphorsulfonic acid fully doped polyaniline emeraldine salt: conformations in different solvents studied by an ultraviolet/visible/near-infrared spectroscopic method. Chem. Mater. 7, 443-445 (1995).

35 Polk, B. J., Potje-Kamloth, K., Josowicz, M. \& Janata, J. Role of protonic and charge transfer doping in solid-state polyaniline. J. Phys. Chem. B 106, 11457-11462 (2002).

36 Kulszewicz-Bajer, I., Rozalska, I. \& Kurylek, M. Synthesis and spectroscopic properties of aniline tetramers. New. J. Chem. 28, 669-675 (2004).

37 Long, S. M., Brenneman, K. R., Saprigin, A., Kohlman, R. S., Epstein, A. J., Angelopoulos, M., Buchwalter, S. L., Rossi, A., Zheng, W. \& MacDiarmid, A. G. Aggregation and interchain 'self' doping in emeraldine base. Synth. Met. 84, 809-810 (1997).

38 Hammond, R. B., Roberts, K. J., Smith, E. D. L. \& Docherty, R. Application of a computational systematic search strategy to study polymorphism in phenazine and perylene. J. Phys. Chem. B 103, 7762-7770 (1999).

39 Nechtschein, M., Santier, C., Travers, J. P., Chroboczek, J., Alix, A. \& Ripert, M. Water effects in polyaniline: NMR and transport properties. Synth. Met. 18, 311-316 (1987).

40 Tang, S. J., Lin, S. M., Chiu, K. C., Wu, Y. Y. \& Yeh, J. M. Effects of dynamic vacuumpumping and temperature dependence of dark electrical conductivity in polyaniline films made by various pressing pressures. J. Phys. D: Appl. Phys. 41, 125401 (2008).

$41 \mathrm{Kriz}$, J., Starovoytova, L., Trchova, M., Konyushenko, E. N. \& Stejskal, J. NMR investigation of aniline oligomers produced in the early stages of oxidative polymerization of aniline. J. Phys. Chem. B 113, 6666-6673 (2009).

42 Pouget, J. P., Jozefowicz, M. E., Epstein, A. J., Tang, X. \& MacDiarmid, A. G. X-ray structure of polyaniline. Macromolecules 24, 779-789 (1991).

43 Kahol, P. K., Pinto, N. J., Berndtsson, E. J. \& McCormick, B. J. Electron localization effects on the conducting state in polyaniline. J. Phys. Condens. Matter. 6, 5631-5638 (1994).

44 Wei, Y., Hariharan, R. \& Patel, S. A. Chemical and electrochemical copolymerization of aniline with alkyl ring-substituted anilines. Macromolecules 23, 758-764 (1990).

45 Chen, L., Sun, L. J., Luan, F., Liang, Y., Li, Y. \& Liu, X. X. Synthesis and pseudocapacitive studies of composite films of polyaniline and manganese oxide nanoparticles. J. Power Sources 195, 3742-3747 (2010).

46 Yoshikawa, H., Hino, T. \& Kuramoto, N. Effect of temperature and moisture on electrical conductivity in polyaniline/polyurethane (PANI/PU) blends. Synth. Met. 156, 1187-1193 (2006)

47 Cristovan, F. H., Lemos, S. G. \& Pereira, E. C. Systematic evaluation of the preparation of conducting PANI/ABS blends. J. Appl. Polym. Sci. 116, 825-831 (2010). 